\title{
BOUNDEDNESS FOR RIESZ-TYPE POTENTIAL OPERATORS ON HERZ-MORREY SPACES WITH VARIABLE EXPONENT
}

\section{JIANGLONG WU}

Abstract. In this paper, the Riesz-type potential operator of variable order $\beta(x)$ is shown to be bounded from the Herz-Morrey spaces $M \dot{K}_{p_{1}, q_{1}(\cdot)}^{\alpha, \lambda}\left(\mathbb{R}^{n}\right)$ with variable exponent $q_{1}(x)$ into the weighted space $M \dot{K}_{p_{2}, q_{2}(\cdot)}^{\alpha, \lambda}\left(\mathbb{R}^{n}, \omega\right)$, where $\omega=(1+|x|)^{-\gamma(x)}$ with some $\gamma(x)>0$ and $1 / q_{1}(x)-$ $1 / q_{2}(x)=\beta(x) / n$ when $q_{1}(x)$ is not necessarily constant at infinity. It is assumed that the exponent $q_{1}(x)$ satisfies the logarithmic continuity condition both locally and at infinity and $1<q_{1}(\infty) \leqslant q_{1}(x) \leqslant\left(q_{1}\right)_{+}<\infty\left(x \in \mathbb{R}^{n}\right)$.

Mathematics subject classification (2010): 42B20, 47B38. estimate.

Keywords and phrases: Herz-Morrey space, Riesz potential, Lebesgue space, variable exponent, weighted

\section{REFERENCES}

[1] O. KovÁČIK AND J. RÁKosníK, On spaces $L^{p(x)}$ and $W^{k, p(x)}$, Czechoslovak Mathematical Journal, 41, 4 (1991), 592-618.

[2] D. CruZ-Uribe, L. Diening And A. Fiorenza, A new proof of the boundedness of maximal operators on variable Lebesgue spaces, Bollettino della Unione Matematica Italiana, 2, 1 (2009), $151-173$.

[3] D. Cruz-Uribe, A. Fiorenza, J. Martell and C. Pérez, The boundedness of classical operators on variable $L^{p}$ spaces, Ann. Acad. Sci. Fenn. Math., 31 (2006), 239-264.

[4] D. Cruz-Uribe, A. Fiorenza And C. Neugebauer, The maximal function on variable $L^{p}$ spaces, Ann. Acad. Sci. Fenn. Math., 28 (2003), 223-238.

[5] L. Diening, P. Harjulehto, P. Hästö And M. RuZicka, Lebesgue and Sobolev Spaces with Variable Exponents, Springer-Verlag, Lecture Notes in Mathematics, Vol. 2017, Berlin,2011.

[6] D. CRUZ-URibe AND A. FiorenzA, Variable Lebesgue Spaces: foundations and harmonic analysis, Birkhäuser/Springer, Applied and Numerical Harmonic Analysis, Heidelberg, 2013.

[7] L. Diening, Maximal functions on Musielak-Orlicz spaces and generalized Lebesgue spaces, Bull. Sci. Math., 129 (2005), 657-700.

[8] L. DiEning, Maximal functions on generalized Lebesgue spaces $L^{p(\cdot)}$, Mathematical Inequalities and Applications, 7, 2 (2004), 245-253.

[9] L. Diening, P. Harjulehto, P. Hästö, Y. Mizuta And T. Shimomura, Maximal functions in variable exponent spaces: limiting cases of the exponent, Ann. Acad. Sci. Fenn. Math., 34 (2009), 503-522.

[10] T. Kopaliani, Infimal convolution and Muckenhoupt $A_{p(\cdot)}$ condition in variable $L^{p}$ spaces, Arch. Math., 89, 2 (2007), 185-192.

[11] A. LERNER, On some questions related to the maximal operator on variable $L^{p}$ spaces, Trans. Amer. Math. Soc., 362 (2010), 4229-4242.

[12] A. NEKVINDA, Hardy-Littlewood maximal operator on $L^{p(x)}\left(\mathbb{R}^{n}\right)$, Math. Inequal. Appl., 7, 2 (2004), $255-265$.

[13] L. PICK AND M. RUZ̆IC̆KA, An example of a space $L^{p(\cdot)}$ on which the Hardy-Littlewood maximal operator is not bounded, Expo. Math., 19 (2001), 369-371. 
[14] A. Almeida AND D. DRIHEM, Maximal, potential and singular type operators on Herz spaces with variable exponents, Journal of Mathematical Analysis and Applications, 394, 2 (2012), 781-795.

[15] S. S Aмко, Variable exponent Herz spaces, Mediterranean Journal of Mathematics, 10, 4 (2013), 2005-2023.

[16] S. SAmKo, Erratum to "Variable exponent Herz spaces", Mediterr. J. Math. DOI: 10.1007/s00009013-0285-X,2013, Mediterranean Journal of Mathematics, 10, 4 (2013), 2027-2030.

[17] A. Almeida, J. HaSAnov And S. SAmko, Maximal and potential operators in variable exponent Morrey spaces, Georgian Mathematical Journal, 15, 2 (2008), 195-208.

[18] M. IZUKI, Boundedness of sublinear operators on Herz spaces with variable exponent and application to wavelet characterization, Analysis Mathematica, 36 (2010), 33-50.

[19] J. L. WU, Boundedness of some sublinear operators on Herz-Morrey spaces with variable exponent, Georgian Mathematical Journal, 21, 1 (2014), 101-111.

[20] V. Guliyev, J. HaSAnov And S. SAmKo, Boundedness of the maximal, potential and singular operators in the generalized variable exponent Morrey spaces, Mathematica Scandinavica, 107, 2 (2010), 285-304.

[21] V. Guliyev, J. Hasanov And S. Samko, Maximal, potential and singular operators in the local "complementary" variable exponent Morrey type spaces, Journal of Mathematical Analysis and Applications, 401, 1 (2013), 72-84.

[22] M. IZUKI, Fractional integrals on Herz-Morrey spaces with variavle exponent, Hiroshima Math J, 40 (2010), 343-355.

[23] S. S Amко, Convolution and potential type operators in $L^{p(x)}$, Integral Transforms and Special Functions, 7, 3-4 (1998), 261-284.

[24] P. Hëstö, Local-to-global results in variable exponent spaces, Mathematical Research Letters, 16, 2 (2009), 263-278.

[25] V. Guliyev, J. Hasanov And S. SAmko, Boundedness of maximal, potential type, and singular integral operators in the generalized variable exponent Morrey type spaces, Journal of Mathematical Sciences, 170, 4 (2010), 423-443.

[26] L. Diening, Riesz potential and Sobolev embeddings on generalized Lebesgue spaces and Sobolev spaces $L^{p(\cdot)}$ and $W^{k, p(\cdot)}$, Mathematische Nachrichten, 268 (2004), 31-43.

[27] V. Kokilashvili And S. Samko, On Sobolev theorem for Riesz type potentials in the Lebesgue spaces with variable exponent, Zeitschrift für Analysis und ihre Anwendungen(Journal for Analysis and its Applications), 22, 4 (2003), 899-910.

[28] V. Guliyev And S. S Amko, Maximal, Potential and singular operators in the generalized variable exponent Morrey spaces on unbounded sets, Journal of Mathematical Sciences, 193, 2 (2013), 228248.

[29] P. Zhang And J. L. Wu, Boundedness of commutators of the fractional Hardy operators on HerzMorrey spaces with variable exponent, Advances in Mathematics (China), In Press. 